\title{
논문 2014-09-07
}

\section{SIFT와 다중측면히스토그램을 이용한 다중물체추적 \\ (Multiple Object Tracking Using SIFT and Multi-Lateral Histogram)}

\author{
전 정 수, 문 용 호, 하 석 운* \\ (Jung-Soo Jun, Yong-Ho Moon, Seok-Wun Ha)
}

\begin{abstract}
In multiple object tracking, accurate detection for each of objects that appear sequentially and effective tracking in complicated cases that they are overlapped with each other are very important. In this paper, we propose a multiple object tracking system that has a concrete detection and tracking characteristics by using multi-lateral histogram and SIFT feature extraction algorithm. Especially, by limiting the matching area to object's inside and by utilizing the location informations in the keypoint matching process of SIFT algorithm, we advanced the tracking performance for multiple objects. Based on the experimental results, we found that the proposed tracking system has a robust tracking operation in the complicated environments that multiple objects are frequently overlapped in various of directions.
\end{abstract}

Keywords : Multiple object, Detection, Tracking, Multi-lateral histogram, SIFT

\section{I. 서 론}

다중의 물체를 인식하고 추적함에 있어서 해결 되어야 하는 선결 과제는 연속적으로 출현하는 물 체들을 개별적으로 탐지하는 일이다. 단일 물체에 대해서는 연속하는 두 프레임의 그레이 영상들의 밝기 차를 이용하여 물체의 윤곽을 구하고 측면 히 스토그램[1]을 통해 물체의 영역을 탐지하고 있으 며, 히스토그램은 단순 객체로써의 홍채 인식이나 물체 인식 연구에 널리 사용되고 있다[2-4]. 본 연 구의 목표인 다중의 물체가 출현하는 경우에는 물 체들의 영역이 중복되게 되어 이들을 구별할 수가 없는 문제점을 가지고 있다. 이를 해결하기 위해서 본 연구에서는 차 영상에서 먼저 탐지된 물체의 수 평 축 히스토그램 영역을 보전하고 그 다음에 대응

*Corresponding Author (swha@gnu.ac.kr)

Received: 21 Oct. 2013, Revised: 2 Dec. 2013, Accepted: 4 Dec. 2013.

S.W. Ha, Y.H. Moon: Gyeongsang national University

J.S. Jun: Aero master Corporation ※ 이 연구는 2013년도 경상대학교 연구년제연구 교수 연구지원비에 의하여 수행되었음
하는 수직축 히스토그램 영역을 세분하는 단순한 방법을 적용함으로써 연속하는 다중 물체를 쉽게 탐지하는 다중측면히스토그램 방법을 적용하였다. 그러나 여러 물체가 가까이 접근함으로써 발생하는 물체 영역의 중복은 피할 수가 없으며 이는 물체들 의 불변 특징들을 활용하여 해결할 수밖에 없다. 다 중측면히스토그램을 활용하여 탐지된 개별 물체들 을 추적하기 위해서는 이들의 불변 특징들을 구하 여 비교해야 한다. 물체들의 불변 특징을 구하는 기 존의 알고리즘들에는 D. G. Lowe가 제시한 $\mathrm{SIFT}[5]$ 와 그의 변형들인 GLOH[6], SURF[7] 등 의 방법들이 있다. SIFT는 물체의 크기, 잡음, 밝 기, 국부 왜곡에 강인한 특징을 제공하고 있다. $\mathrm{GLOH}$ 는 SIFT에 비해 구조화된 영상에 대해 나은 성능을 발휘하지만 그리드의 크기가 2 배로 커지는 면이 있으며, SURF는 영상 피라미드를 사용하는 대신 Harr 웨이블렛을 사용함으로써 SIFT에 비해 빠른 처리와 나은 성능을 가진 것으로 연구되고 있 다. 그러나 본 연구에서는 키포인트 정합과정 중에 서 객체 내부에 국한되고 보다 정확한 위치 정보를 동시에 활용하기 위해, 이를 제공하는 SIFT 알고리 즘을 적용하였다. SIFT 처리를 통해 구해진 특징 키포인트들에는 특정 임계값을 기준으로 위치가 정 합되지 않는 것들이 필연적으로 발생하게 되고 물 


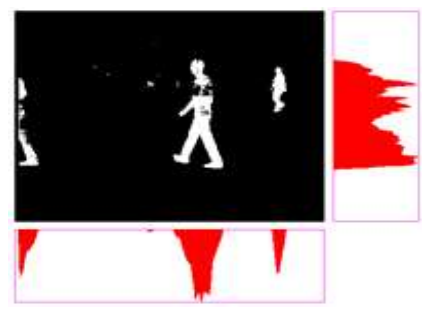

(a)

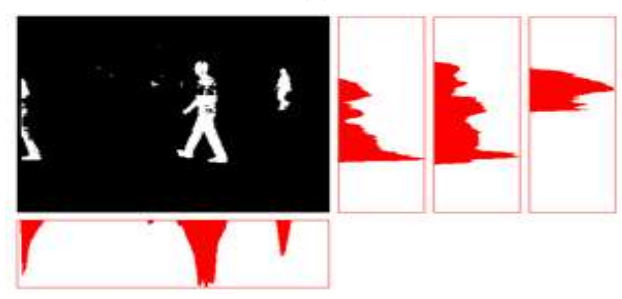

(b)

그림 1. 측면히스토그램 (a) 과 다중측면히스토그램 (b)

Fig. 1 Lateral Histogram (a) and Multi-Lateral Histogram (b)

체 추적에 영향을 주는 문제가 발생한다. 이를 제거 하면 추적 성능을 증가시킬 수는 있으나 작은 물체 에 대해서는 키포인트의 수가 감소하여 추적에 실 패할 수 있다. 본 연구에서는 이들 위치 비정합 키 포인트들을 추적을 위한 비교 과정에 참여시키지 않게 함으로써 물체가 작아질 때에도 추적이 가능 하게 하였다. 본 논문의 구성은 다음과 같다. 2 장에 서는 다중측면히스토그램과 다중물체탐지 방법과 SIFT 알고리즘을 이용한 불변 특징 추출에 대해서 나타내었으며, 3장에서는 동영상에 대한 다중 물체 추적 실험 및 결과, 그리고 4 장에서 결론을 맺었다.

\section{II. 다중 물체 탐지 및 추적}

\section{1. 다중측면히스토그램}

측면히스토그램(Lateral Histogram)은 그레이 레벨 영상에서 수평 축 방향과 수직 축 방향으로 동일한 행과 열에 대해 픽셀들의 밝기 값을 누적시 켜 놓은 것으로 영상 내에서 특정 물체의 영역과 모양을 구할 때 사용되어 왔다 $[1-4,8]$. 한 영상 내에 여러 개의 물체가 존재하는 경우에는 물체들 이 늘어서 있는 방향으로 개별 물체의 히스토그램 이 중복되어 단일 물체로 판단되는 문제가 발생한

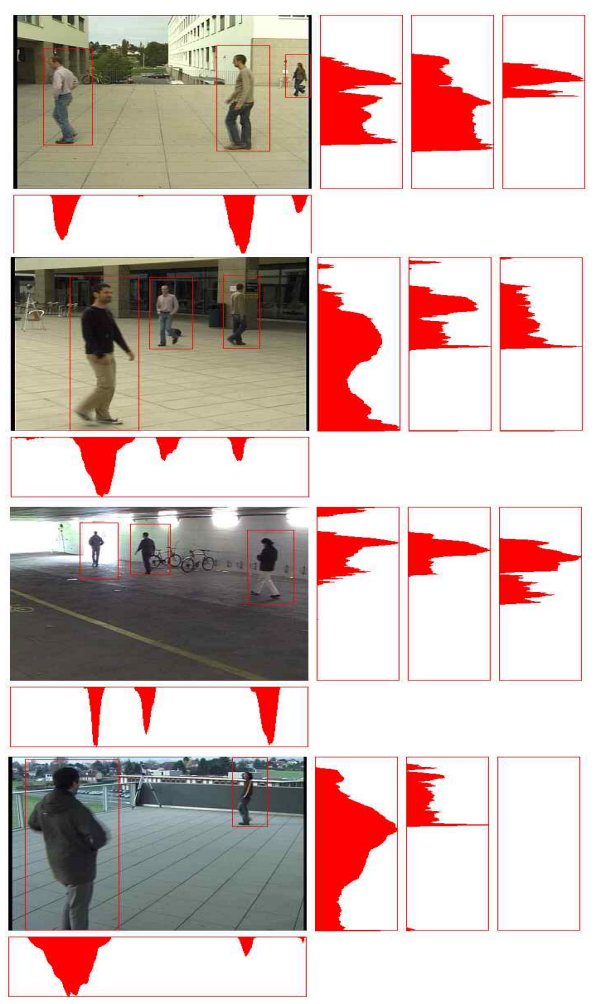

그림 2. 다중측면히스토그램에 의한 다중 물체 영역 탐지 결과

Fig. 2 Detection Results of Multiple

Object Area Using Multi-Lateral Histogram

다. 이는 다중 물체들이 늘어서 있는 축 방향의 히 스토그램에 대해 먼저 물체 영역을 구분한 다음, 개 별 영역별로 상대 축의 히스토그램 영역을 구함으 로써 개별 물체 영역을 탐지하는 측면히스토그램의 한 쪽 측면 표현 자료 수를 확장한 다중측면히스토 그램(Multi-Lateral Histogram) 방법을 적용하면 쉽게 해결할 수 있다. 하지만 다중측면히스토그램에 서도 물체들이 근접하거나 중복되는 경우에는 이들 물체들을 구분할 수 없다. 이를 다중 물체 추적에 응용하기 위해서는 물체가 근접하거나 중복되기 전 의 프레임 영상에서 이들 물체들의 개별적인 특징 들을 구하여 보관함으로써 물체 분별에 적용한다면 다중측면히스토그램 방법은 매우 유용한 물체 탐지 방법이 될 수 있다.

그림 1 은 측면히스토그램과 다중측면히스토그램 을 보여주고 있다. (a)에서는 수직축에서 물체들이 모두 중복되어 나타나지만 (b)에서는 개별 히스토그 램이 구성되는 것을 보여준다. 
다중측면히스토그램을 통해 다중 물체 영역을 탐지하는 과정은 다음과 같다.

1) 수평축 방향으로 각각 히스토그램을 구하고 스 무딩 처리를 행한다.

2) 누적값의 통계 처리를 통해 임계값을 구한다.

3) 임계값보다 높은 값이 연속으로 존재하는 영역 을 물체들의 개별 영역으로 결정한다.

4) 개별 수평영역에 대응하는 수직축 히스토그램을 구하고 스무딩 처리를 행한다.

5) 2)와 3)을 반복한다.

6) 영상으로부터 수평축과 수직축의 개별 히스토그 램 영역들에 대응하는 영역을 다중 물체들이 존 재하는 영역으로 결정한다.

그림 2는 다중측면히스토그램을 적용하여 구해 진 다중 물체 영역 탐지 결과를 보여준다.

\section{2. 다중 물체 탐지}

동영상에서 다중 물체를 추적하기 위해서는 개 별 물체들의 불변하는 특징들을 구해야 할 필요가 있다. 측면히스토그램을 사용하여 구한 개별 물체들 이 존재하는 영역은 물체들의 주변 영역들도 포함 하고 있기 때문에 특징을 구할 때 이들 주변 영역 의 특징도 동시에 처리되지 않도록 하기위해서는 물체에 해당하는 영역만을 정확하게 추출해서 탐지 해야 한다.

물체 탐지 과정은 다음과 같으며, 처리 시간과 주변 배경에서의 밝기 변화에 의한 영향을 최대한 줄이기 위해서 현재 프레임에서 다중히스토그램으 로 탐지된 물체 영역과, 대응하는 배경 프레임에서 의 물체 영역에 대해서만 탐지 과정을 적용한다.

1) 배경 프레임과 현재 프레임 영상에 대해 해당하 는 물체 영역들에 대해 저역통과필터(Gaussian, $13 \times 13)$ 를 처리한다.

2) 해당하는 물체 영역들에 대해서만 두 프레임간 의 밝기 차(Difference)를 구한다.

3) 콘트라스트 조정(Equalization)을 통해 해당 영 역 내에서 물체와 그 외 영역간의 밝기 차를 증 폭시킨다.

4) 이진화(Binarization) 과정을 통해 물체 영역 내 에서 물체와 주변 영역을 구분함으로써 물체를 탐지한다.

그림 3은 위의 처리 과정에서의 결과들을 보여

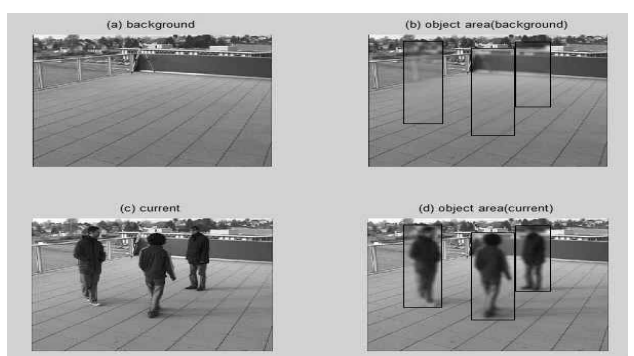

(a) 물체 영역에 대한 필터링 결과

(a) Filtering results for the area of objects

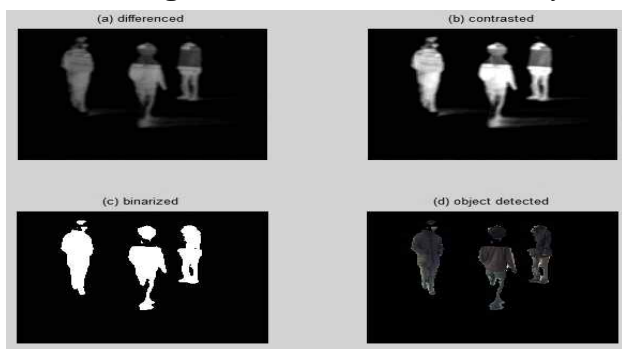

(b) 탐지된 물체 영역

(b) Detected area of objects

그림 3. 다중 물체 탐지 결과

Fig. 3 Results of Multiple Object Detection

주고 있다. (a)에서는 다중측면히스토그램 방법에 의해 탐지된 물체 영역들에 대해서만 현재와 배경 프레임에서의 저역통과필터를 적용한 결과를 보여 주고 있으며, (b)에서는 차분, 콘트라스트조정, 이진 화 후에 물체가 탐지된 결과를 보여준다.

그림 3 에서 탐지된 물체를 보면 신체의 일부분 이 탐지되지 않았지만 물체만을 정확하게 탐지하기 때문에 다음에 오는 물체 특징 추출 과정에서 효율 적이고 견고한 특징 추출에 기여할 수 있다.

\section{3. 다중 물체 불변 특징 추출}

다중 물체 추적을 위해서는 탐지된 다중 물체들 에 대해 이들 간에 구별되는 불변 특징을 구해야 한다. 본 연구에서는 최근의 연구들에서 제시된 물 체의 불변 특징(Invariant Features)을 구하는 알고 리즘들 중에서 물체 탐지 및 인식에 널리 사용되고 있는 Lowe의 SIFT(Scale Invariant Feature Transform) 알고리즘을 적용하였으며, 전후 프레임 에서 SIFT에 의해 추출된 물체 특징들 간의 정합에 서 발생되는 부정합 특징들을 제거함으로써 추적 효율을 향상시키는 방법을 적용하였다. 


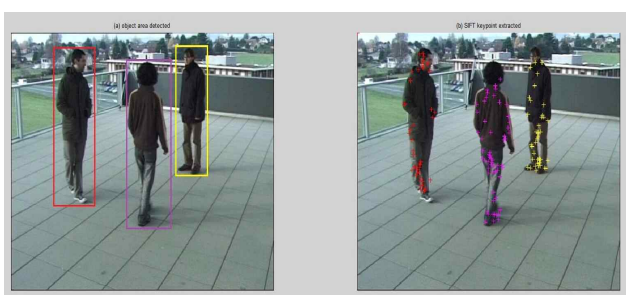

그림 4. 다중 물체의 SIFT 키포인트 추출 결과

Fig. 4 Extraction Results of SIFT Keypoints for Multiple Objects

$\mathrm{SIFT}$ 알고리즘의 처리 과정은 다음과 같이 크게 네 단계를 거친다.

1) Scale-space Extrema Detection: 첫 단계로써 DoG(Difference of Gaussians) 함수를 적용하 여 크기와 방향에 불변하는 키포인트들을 구한 다.

2) Keypoint Localization: 밝기와 위치에 관해 안 정성 있는 키포인트들을 선별한다.

3) Orientation Assignment: 밝기 변화에 따른 방 향 정보들을 할당한다.

4) Keypoint Description: 불변 특징을 결정지우는 키포인트들에 대해 주변 포인트들의 밝기 변화 크기와 방향들로부터 계산된 불변 특징 정보를 히스토그램 형식의 벡터로 기술한다.

다음 식 (1)은 SIFT 알고리즘을 적용한 결과 추 출된 특징들을 포함하는 하나의 벡터로 기술하는 키포인트 기술자(Keypoint Descriptor)를 나타낸다.

$$
[\text { im }, \text { des, loc }]=\operatorname{SIFT}(\text { im age })
$$

여기서 $i m$ 은 물체들이 존재하는 시험 영상의 픽 셀 값들을 가지고 있고, des는 기술자 벡터 (Descriptor Vector)의 매트릭스이며, $l o c$ 는 모든 키포인트들의 위치, 크기, 방향 값들을 가지고 있다. 물체 탐지와 추적에는 이 loc 변수의 특징 값들을 사용하게 된다.

그림 4 는 탐지된 다중 물체들에 대해 SIFT 알 고리즘을 적용하여 추출된 다중 물체들의 불변 특 징 키포인트들을 보여주고 있다.

$\mathrm{SIFT}$ 알고리즘을 적용하여 추출된 키포인트의 정보를 활용하여 다중 물체 추적을 행하기 위해서 는 전 프레임과 현재 프레임에서 동일한 물체들의 키포인트들 간의 정합(Matching) 과정이 반드시 필
요하다. 기존의 SIFT 알고리즘을 적용할 경우, 물 체의 방향이 거의 변하지 않는 경우에는 키포인트 들의 특징들이 거의 일정하여 정합되는 키포인트들 의 수가 많아서 추적에 용이하지만, 물체의 방향이 심하게 변하는 경우에는 정합되는 키포인트의 수가 적어서 추적이 힘들어진다. 또한 이 정합 키포인트 들 중에는 그 위치에 있어서 현저하게 차이가 있음 에도 정합으로 결정되는 부정합 키포인트들이 존재 하여 정합 키포인트가 적은 경우의 추적에는 큰 영 향을 주게 된다. 따라서 보다 효율적인 추적을 위해 서는 이들 부정합 키포인트들이 정합에 참여하지 못하도록 할 필요가 있다.

키포인트들 간의 정합 과정에서는 먼저 전 프레 임내의 물체에 대한 $m$ 개의 키포인트와 현재 프레 임 내의 동일 물체에 대한 $n$ 개의 키포인트들 간의 거리를 계산한다. 거리 $d_{i j}$ 는 다음 식 (2)와 같이 두 기술자 벡터들 간의 내적에 의해 구할 수 있다.

$$
d_{i j}=\cos ^{-1}\left(d e s_{R i} \cdot \operatorname{des}{ }_{C j}\right)
$$

여기서 $i=1, \ldots, n, j=1, \ldots, m, d e s_{R i}$ 는 전 프레임 에서의 $i$ 번째 기술자 벡터, $\operatorname{des}_{C j}$ 는 현재 프레임에 서의 $j$ 번째 기술자 벡터를 나타낸다.

다음으로는 가장 가까운 이웃 키포인트와의 거 리와 두 번째 가까운 이웃 키포인트와의 거리 비를 식 (3)과 같이 계산한다.

$$
\text { dist Ratio }=\frac{\text { the closest distance }}{\text { the second }- \text { closest distance }}
$$

이 distRatio가 Lowe의 실험에서 제시한 적정 거리비율 0.8 을 기준으로 이 보다 더 작으면 정합, 그렇지 않으면 부정합으로 간주한다.

$$
\text { match }= \begin{cases}\text { accept } & \text { if distRatio } \leq 0.8 \\ \text { reject } & \text { if distRatio }>0.8\end{cases}
$$

정합으로 판정된 키포인트들 중에서 다음 식 (5) 와 (6)을 통해 위치 정보를 적용하여 위치 정합 키 포인트들을 추출한다.

$$
\begin{gathered}
d_{R C}=\sqrt{\left(x_{C}-x_{R}\right)^{2}+\left(y_{C}-y_{R}\right)^{2}} \\
\text { location-matched }=\left\{\begin{array}{lll}
y e s & \text { if } d_{R C} \leq d_{t h} \\
n o & \text { if } & d_{R C}>d_{t h}
\end{array}\right.
\end{gathered}
$$




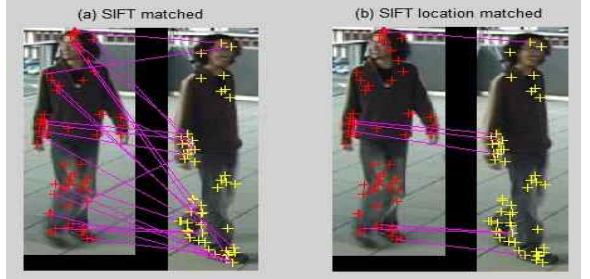

그림 5. SIFT 키포인트 정합과 위치 정합 결과 Fig. 5 Results of SIFT Keypoint Matching and Keypoint Location Matching

여기서 $\left(x_{R}, y_{R}\right)$ 은 전 프레임의 키포인트 위치, $\left(x_{C}, y_{C}\right)$ 는 현재 프레임의 대응 키포인트의 위치를 나타내며, $d_{t h}$ 는 허용 임계 거리를 나타내며, 여기 서는 실험 동영상에 따라 물체의 동작 변화를 고려 하여 5 8 픽셀로 설정하였다.

다음 그림 5의 (a)에서는 두 프레임 영상에서 동 일 물체의 키포인트들 간의 정합 결과를 보여주고 있으며 정합된 키포인트의 수가 많이 존재하는 것 을 나타내고 있으며, (b)에서는 정합된 키포인트들 의 위치 정보를 토대로 재구성한 정합도가 높은 키 포인트들을 보여주고 있다.

\section{4. 다중 물체 추적}

SIFT 키포인트 정합에서 위치 정보를 고려하여 추출한 키포인트 정합을 이용하여 다중의 물체를 추적한다. 추적을 실행하는 과정은 다음과 같다.

1) 전 프레임에서 추출된 다중 물체들에 대해 키포 인트 특징 정보들을 개별적으로 저장한다.

2) 현재 프레임에서 추출된 다중 물체들의 키포인 트 특징 정보들을 1)에서의 물체별 키포인트들 과 정합을 실행한다. 위치 정합까지의 정합 키포 인트 수가 가장 많은 물체를 정합 물체로 간주 한다.

Matching - Object $_{i}=$ case $\left[\max \left\{m_{i 1}, m_{i 2}, \ldots m_{N}\right\}\right]$

여기서 $i=1, \ldots, M, M$ 은 전 프레임에서의 물체의 개수, $N$ 은 현재 프레임에서의 물체의 개수이다. $m_{i j}$ 는 전 프레임의 $i$ 번째 물체와 현재 프레임의 $j$ 번째 물체 사이의 위치 정합 키포인트 수를 나 타낸다.

3) 전 프레임에서의 물체 키포인트 특징 기술자 중 에서 정합 결과, 현재 프레임에서의 모든 물체 특징과 정합되지 않으면 이 물체는 사라지는 것 으로 간주한다.

$$
O_{\text {disappear }} \cong\left[\text { if all } m_{i j}=0\right]
$$

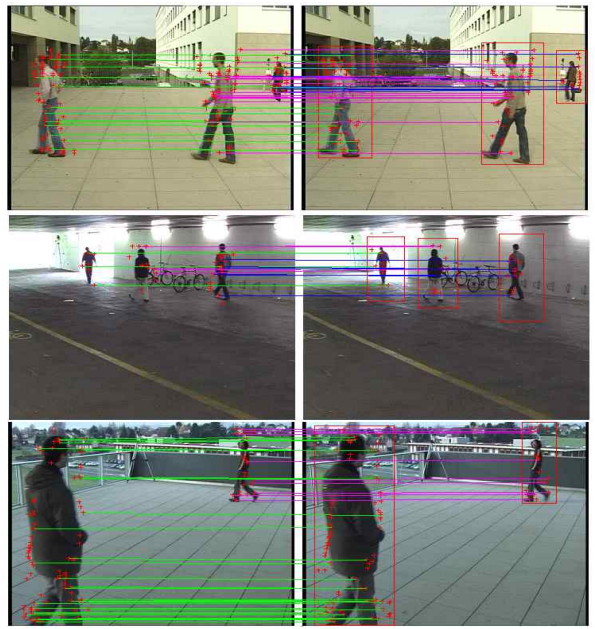

그림 6. SIFT 키포인트 정합을 이용한 다중 물체 정합 결과

Fig. 6 Matching Results of Multiple Objects Using SIFT Keypoint Matching

4) 현재 프레임을 대상으로 전 프레임 물체들과의 정합에서 전 프레임의 모든 물체들과 정합되지 않으면 새롭게 출현하는 물체로 간주한다.

$$
O_{\text {appear }} \cong\left[\text { if all } m_{j i}=0\right]
$$

여기서 $m_{j i}$ 는 현재 프레임의 $j$ 번째 물체와 $i$ 번 째 물체와의 위치 정합 키포인트 수를 나타낸 다. 그림 6은 세 가지 동영상에 대해 SIFT 키포 인트 정합 결과를 나타내고 있으며, 물체들 간 에 정합이 원활하게 이루어지고 있음을 보여준 다.

\section{II. 다중 물체 추적 실험 및 결과}

다중측면히스토그램을 적용하여 한 프레임 영상 내에 존재하는 다수의 물체들을 탐지하고, 위치 정 보를 고려한 SIFT 키포인트 불변 특징을 적용하여 전 프레임과 현재 프레임 물체들 간의 정합 정도를 구함으로써 다중 물체를 추적할 수 있는 시스템을 제시하였다.

제시하는 다중 물체 추적 시스템의 추적 성능을 평가하기 위해서 프랑스 Eclole Polytechnique[9] 에서 제공하는 세 가지 동영상을 적용하여 실험하 였다. 동영상 1 은 보행자 물체 수가 4 , 동영상 2 는 물체 수가 4 , 동영상 3 은 물체 수가 2이다.

다음 그림 7 은 동영상 1 에 대해 네 명의 보행자 


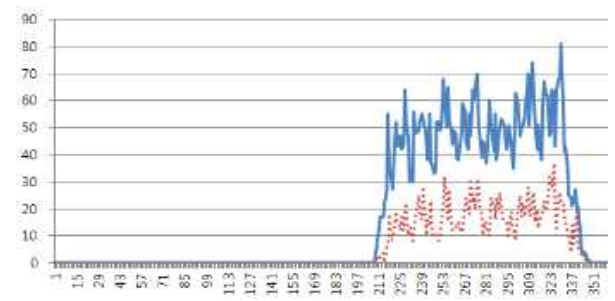

그림 7 . 동영상 1 에서 보행자 1 에 대한 키포인트 정합 결과

Fig. 7 Keypoint Matching Results for Pedestrian 1 in Video 1

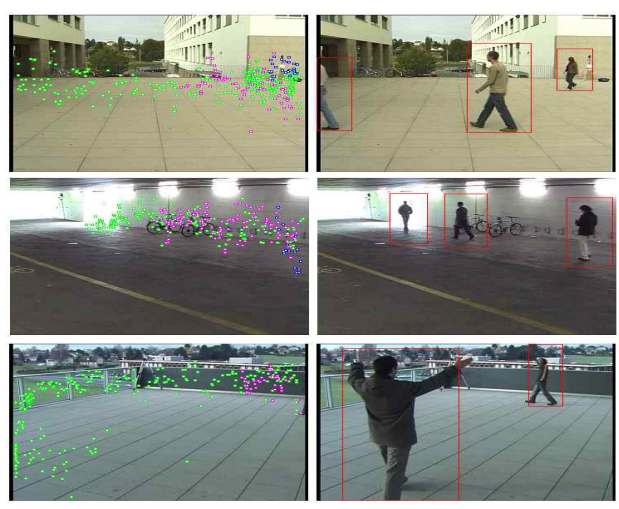

그림 8. 다중 물체 탐지 및 추적 궤적

Fig. 8 Multiple Objects Detection and Tracks

물체들 중에서 보행자 1 에 대한 현재 프레임에서의 키포인트 수와 정합되는 키포인트 수를 전체 프레 임에 대해서 그래프로 나타낸 것이다. 그림 7 에서 파란색 그래프는 전체 프레임에 대해 SIFT에 의해 생성된 키포인트 수를 나타내었으며, 붉은 점선은 위치 정보를 고려한 정합 키포인트 수를 나타내었 다. 정합되는 키포인트의 수는 전체 키 포인트 수의 평균에 비해 약 3 분의 1 로 줄어들었다.

그림 8에서는 세 가지 동영상에서 다중 물체들 의 탐지와 추적 궤적을 보여주고 있다.

전체 프레임 수를 $\mathrm{c}$, 추적에 성공한 프레임의 수 를 $\mathrm{a}$, 추적에 실패한 프레임 수를 $\mathrm{b}$ 라 하면, 식 (10)에 의해 계산한 결과,

$$
\text { 추적성공율 }=\frac{a}{c} \text {, 추적 실패율 }=\frac{b}{c}
$$

표 1 에서와 같이 동영상 1 의 624 프레임에 대 해서는 $89 \%$ 인 555 프레임, 동영상 2의 627 프레
표 1. 다중 물체 추적 결과

Table 1. Results of Multiple Objects Tracking

\begin{tabular}{|c|c|c|}
\hline & 추적 성공률 $(\%)$ & 추적 실패율 $(\%)$ \\
\hline 동영상 1 & 89 & 11 \\
\hline 동영상 2 & 78 & 22 \\
\hline 동영상 3 & 87 & 13 \\
\hline
\end{tabular}

표 2. 칼만 필터의 경우와 비교한 결과

Table 1. Compared Results with Kalman Filter

\begin{tabular}{|c|c|c|}
\hline & $\operatorname{SIFT}(\%)$ & $\operatorname{Kalman}(\%)$ \\
\hline 동영상 1 & 89 & 93 \\
\hline 동영상 2 & 78 & 52 \\
\hline 동영상 3 & 87 & 59 \\
\hline
\end{tabular}

임에 대해서는 $67 \%$ 인 489 프레임, 동영상 3 의 537 프레임에 대해서는 84\%인 467 프레임을 추적 에 성공하였다. 동영상 2 의 경우에는 보행자 물체들 간의 매우 빈번한 중첩으로 인해서 다소 낮은 추적 성공률을 나타내었다.

표 2에서는 칼만 필터를 적용한 경우와 비교한 결과를 나타내었다.

칼만 필터의 경우와 비교하였을 때, 물체가 뚜렷 하고 중첩이 발생하지 않는 동영상 1 에서는 칼만 필터에서 더 나은 성능을 보였으나, 물체가 매우 작 아지면서 배경이 밝아지는 환경이 있는 동영상 2 의 경우에는 칼만 필터에서는 추적에 크게 실패하였으 며, 객체 간에 매우 빈번하게 중첩이 발생하는 동영 상 3 의 경우에는 본 연구 방법에서 보다 우수한 추 적 성능을 나타내었다.

\section{IV. 결 론}

본 연구에서는 다중측면히스토그램 방법을 적용 하여 다중 물체를 손쉽게 탐지하고 물체별 SIFT 알 고리즘을 적용한 키포인트 정합을 통해서 동영상 내의 다중 물체를 추적하는 시스템을 연구하였다.

추적 실험 결과, 출현과 퇴장을 빈번하게 하는 경우에 대해서도 약 $88 \%$ 의 추적 성능을 나타내었 으며, 여러 객체들이 다양하게 중첩이 다발적으로 발생하는 동영상에 대해서도 약 $78 \%$ 의 추적 성능 을 얻을 수 있었다.

향후에는 다중 물체의 추적 방법을 적절하게 개 
선하고, 중첩의 경우에 잘 정합될 수 있는 정합 방 법을 연구하여 추적 성능을 향상시키고자 하며, 동 적 배경 환경에서도 잘 적응하는 방법에 대해서도 연구하고자 한다.

\section{References}

[1] E.R. Davis, "Lateral histogram for efficient object location: Speed versus ambiguity," Pattern Recognition Letters, Vol. 6, No. 3, pp.189-198, 1987.

[2] S. H. Kim, S. Kim, "Implementation of Embedded System for a First Iris identification Based on USN," Journal of IEMEK, Vol. 4, No. 4, pp. 190-194, 2009.(in korean).

[3] Q. Jin, X. Tong, P. Ma, S. "Iris Recognition by New Invariant Feature nDescriptor," Journal of Computational Information Systems, Vol. 9, No. 5, pp.1943-1948, 2013.

[4] H. Zhang, W. Gao, X. Chen, D. Zhao, "Object Detection using Spatial Histogram features," Image and Vision Computing, Vol. 24, No. 4, pp.327-341, 2006.

[5] D.G. Lowe, "Object Recognition form Local Scale-Invariant Features," Proceedings of the International Conference on Computer Vision, pp.1150-1157, 1999.

[6] K. Mikolajczyk, C. Schmid, "A Performance Evaluation of Local Descriptors," IEEE Transations on Pattern Analysis and Machine Intelligence, Vol. 27, No. 10, pp.1615-1630, 2005.

[7] H. Bay, T. Tuytelaars, L.V. Gool, "SURF: Speeded Up Robust Features," Proceedings of the European Conference on Computer Vision, pp.404-417, 2006.

[8] E. Rafajlowicz, "Improving the Efficiency of Computing Defects by Learning RBF Nets with MAD Loss," Proceeding of the International Conference on Artificial Intelligence and Soft Computing, pp.146-153, 2008.

[9] Ecole Polytechnique, Computer Vision Laboratory, http://cvlab.epfl.ch/data/pom/

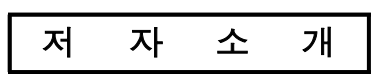

\section{전 정 수}

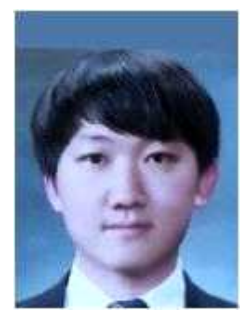

2000년: 경상대학교 정 보과학과 학사.

2002년 경상대학교 정보 과학과 공학석사.

2002년 현재 에어로마 스터 선임연구원.

관심분야: 임베디드소프트웨어, 디지털영상처 리, 항공소프트웨어.

Email:rustys@naver.com

\section{문 용호}

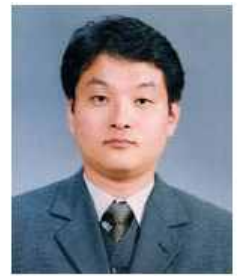

1998년 부산대학교 전자 공학과 공학박사.

1998년 2001년, 삼성전 자 $\mathrm{DM}$ 연구소 책임연구원. 2007년 현재, 경상대학 교 정보과학과 부교수.

2012년 미국 캘리포니아대 학교(UCSB) 교환 교수.

관심분야: 영상처리, 동영상압축, 임베디드시 스템, SoC.

Email:yhmoon5@gnu.ac.kr

\section{하 석 운}

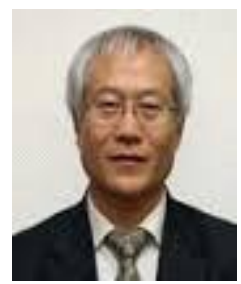

1995년 부산대학교 전자 공학과 공학박사. 2002년 미국 캘리포니아대 학교(UCR) 교환 교수. 1993년 현재, 경상대학교 정보과학과 교수

관심분야: 디지컬영상처리, 임베디드소프트웨어, 컴퓨터비전, 신경망

Email:swha@gnu.ac.kr 